Historic, archived document

Do not assume content reflects current scientific knowledge, policies, or practices. 
Heg84Pro Cup. 3

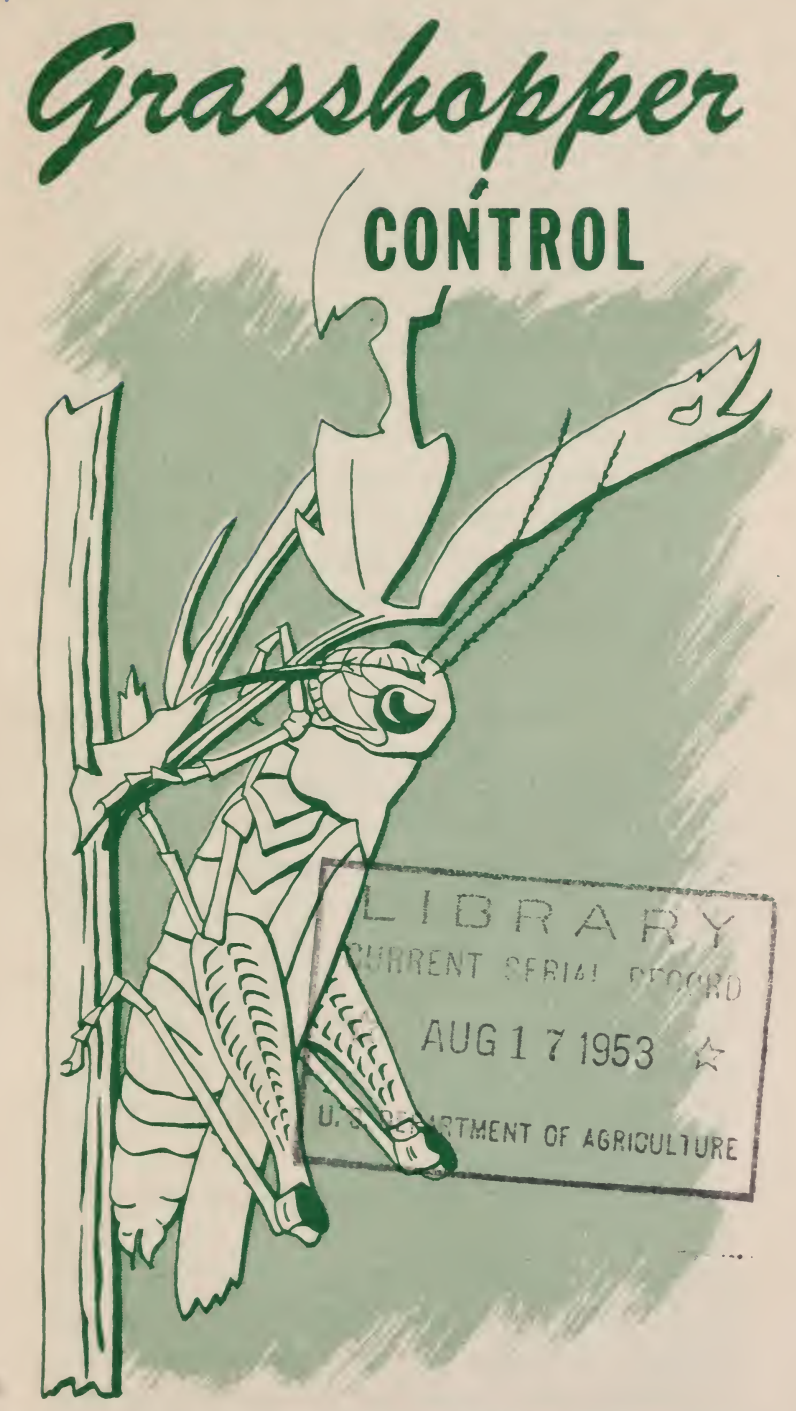

Bureau of Entomology and Plant Quarantine Agricultural Research Administration U.S. Department of Agriculture PA-149 Revised 1953 
GRASSHOPPERS can be controlled with aldrin, chlordane, toxaphene, or heptachlor. These insecticides may be applied as dusts, but sprays give higher initial kill, continue to kill over a longer period, and require less insecticide per acre.

Sprays have replaced baits almost entirely, but baits are still used to control grasshoppers in fall-seeded grain when the plants are only a few inches tall. Sprays are less effective under such conditions, because the treated leaf surface is not large enough to stop migrations of grasshoppers from adjacent untreated vegetation.

\section{Sprays and Dusts}

Formulations and Dosages.--Readymixed oil solutions, emulsifiable concentrates, wettable powders, and dusts in various strengths are obtainable from insecticide dealers. Emulsifiable concentrates and wettable powders should be diluted with water to suit available spraying equipment. The oil solutions may be diluted with kerosene or fuel oil.

Emulsions and oil solutions are less likely to clog nozzles than are wettable-powder sprays. Emulsions are safer than oil solutions for use on tender foliage. Do not use more than 1 gallon of a diluted oil solution per acre. Use heptachlor only on range land.

Whatever the formulation or dilution, in sprays use the following quantities of active ingredient per acre: 
Aldrin .......11/2-2 ounces

Chlordane....1/2 - 1 pound

Heptachlor.... 3 - 4 ounces

Toxaphene.....1-11/2 pounds

If you use a dust, increase these dosages by 50 percent.

Use the lower dosages for young grasshoppers in short, dense, succulent vegetation and on open stands of taller growth when long-continued killing action is not essential.

Use the higher dosages when vegetation is tall and dense or when grasshoppers are adults. When it is necessary to control young grasshoppers before the main hatch is completed, the higher dosages may extend residual action long enough to kill the rest of the hatch and thus save the cost of a second treatment. The higher dosages may also be needed for the treatment of barrier strips or for late-season use when vegetation is maturing, temperatures are high, and grasshoppers are full grown.

The dosages recommended are based on performance in experiments and in general use, and have been endorsed by the State Leaders' Advisory Committee on Grasshopper Control. They should not be expected to cover all local conditions within the many States where grasshopper control is needed. They are offered as a guide to help individuals solve their own problems. If you have any difficulties, consult your county agricultural agent or one of your extension or State entomologists. 
Dieldrin has been used successfully in numerous experiments, but cannot be recommended until the problem of residues on treated crops has been solved.

Lindane, methoxychlor, parathion, and CS-708 (Dilan) have also shown promise in grasshopper control, but they have not been tested so widely as the insecticides listed above. Do not use them unless specifically recommended by your State entomologists.

Time and Methods of Application.-The recommended insecticides are most effective when applied evenly at the right time and in the right place. They may be applied with ground sprayers or dusters, or by airplane. The equipment should be carefully adjusted to give the desired rate of application. Toomuch material is wasteful and increases the danger of harmful residues. Toolittle insecticide also wastes time and materials, because it will not prevent crop losses. Areas treated with less than effective dosages will have to be retreated to obtain control.

Farmers using these insecticides as sprays or dusts for grasshopper control should proceed as follows:

1. Determine the location of threatening infestations of young grasshoppers in relation to the fields planted to crops. Look along roadsides, canal banks, field margins, in idle lands bordering cultivated fields, as well as in the fields themselves. Spray or dust these places when the main hatch 
is completed or when the young grasshoppers begin to move off the hatching grounds, and thus greatly reduce the acreage that otherwise might have to be treated later. Grasshoppers that damage row crops usually hatch in field margins. Timely spraying or dusting of vegetation in such margins will destroy grasshoppers before they move into the fields.

2. To prevent grasshoppers from damaging corn, treat the margins of cornfields and adjacent infested smallgrain fields or weed patches when the small grains begin to mature and before the grasshoppers move into the corn.

3. When an entire alfalfa field is severely infested, it is ordinarily most economical to cut the alfalfa and then apply an insecticide to protect the next cutting. Spray or dust field margins, ditch banks, patches of weeds, or uncut strips of alfalfa where grasshoppers have concentrated. Grasshoppers frequently hatch in large numbers after the first crop has been harvested. To control these insects, spray or dust the next crop before the new growth is more than 6 inches high. This practice protects the new growth and avoids heavy residues at harvest.

4. Grasshoppers on the range can be controlled more completely and economically with sprays than with baits. Use the recommended dosage of insecticide in 1 gallon of oil. Begin control measures when hatching of the 
dominant species is completed, and finish before these species begin to lay eggs.

Protection of the current year's field crops and range forage is no longer the sole aim of grasshopper control. It has been demonstrated that if all economic infestations in a neighborhood are reduced to less than 1 grasshopper per square yard, further control measures will not be needed for several years unless the fields become reinfested through migrations.

Baits

Any of the insecticides recommended for sprays and dusts can be used in a bait formula.

Use enough of the ready-mixed formulation to give the following amounts of active ingredient per 100 pounds of bran or bran-sawdust mixture:
Aldrin ......2 ounces
Chlordane....1/2 pound Heptachlor. ....4 ounces
Toxaphene.....1 pound

For application from the ground use a wet bait. To prepare this bait stir an emulsifiable concentrate or a wettable powder containing the insecticide into water and mix with mill-run bran and sawdust in a single operation. To make 100 pounds of the mixture, use enough water (about 10 to 12 gallons) to make a moist, crumbly mash, 25 pounds of bran, and $31 / 2$ bushels of sawdust ( 3 times the volume of bran). 
Spread wet bait uniformly by hand or with a broadcasting machine at the rate of 20 pounds per acre.

A dry bait, made by impregnating bran with anoil solution of the insecticide, is preferable to a wet bait for application by airplane. It can be applied from the ground from singleoutlet dusters. Do not apply dry bait with a broadcaster designed for handling wet bait.

Dilute the oil solution that you buy with $1 / 2$ gallon of kerosene or fuel oil and spray onto 100 pounds of coarse, drybran. Power bait-mixing machines may be equipped with spraying devices for this purpose. Make every effort to distribute the solution uniformly throughout the bran.

Apply dry bait at the rate of 5 to 10 pounds per acre. This is equivalent to 20 to 40 pounds of wet bait in bran content. Dry bait may be prepared in advance and stored until needed.

\section{PRECAUTIONS}

All the insecticides recommended for grasshopper control are poisonous to man and animals, but the diluted sprays are not dangerous to handle if ordinary precautions are followed. In concentrated form they may cause acute poisoning when in contact with the skin or if inhaled or swallowed.

After spraying or dusting, bathe thor oughly and change to clean clothing. If you spill any spray material on the skin, bathe immediately.

If the insecticide is accidentally swallowed, induce vomiting by taking 
1 tablespoonful of salt in a glass of warm water. Repeat if necessary. Call a doctor.

Store bait where livestock cannot reach it. Do not pile it on the ground. Keep livestock off air strips where planes are being loaded. In loading planes, spill as little as possible, and clean up all spilled bait on the air strips or in surrounding grass or brush.

Do not feed forage or chaff contaminated with these insecticides to poultry or dairy animals, or to meat animals during the last 2 months before slaughter.

If you treat fruits or vegetables with any of these chemicals, do not apply them to the parts of the plants that will be eaten or marketed.

Bees are essential to legume-seed production. To avoid killing bees, do not apply these insecticides to legumes in bloom. If grasshoppers must be controlled at this time to save the seed crop, spray with toxaphene, and then only in the early morning or late evening while bees are inactive. Sprays are less harmful than dusts.

Community Action Needed for Successful Control

Regardless of the method used, grasshopper control is most effective when all property owners in a community cooperate in destroying threatening infestations of grasshoppers wherever they are found.

Prepared by J. R. Parker and F. T. Cowan, Division of Cereal and Forage Insect Investigations. 